\title{
The consumers' view of problems and priorities in nutrition
}

\author{
By J. C. McKenziE, Ilkley College, Ilkley, West Yorkshire
}

\section{Introduction}

In 1963 Brown, McKenzie and Yudkin examined the nutritional knowledge of housewives in a London suburb. Subsequently the findings of national studies on the subject were reported (McKenzie, 1965). Further major studies have been conducted on a fairly regular basis since that date (Margarine and Shortening Manufacturers Association, 1969; British Nutrition Foundation, 1973).

However, the prime concern of these studies has been to look at the level of nutritional knowledge which housewives/consumers possess (in particular the extent to which they can relate nutrients to foods); their views on the role which various nutrients perform in the diet; and their attitude to foods generally. The studies have not directly concerned themselves with the identification of the consumers' view of the problems and priorities in nutrition. Indeed, were consumers to be questioned in this way, it would be probable that they would not be able to very readily identify problems in the nutrition field or to set priorities for their solution.

As such, in order to adequately respond to today's topic, I have felt it necessary both to redefine the problem and to conduct new research to isolate the response.

I believe that the problem may be redefined in the following way; what concerns do people have in terms of food/nutrition? What diseases do men and women in Britain worry about? How far is food seen as a protection from/cause of these diseases?

The study to deal with this problem, has involved a series of group discussions in which the consumers were probed in depth regarding their concerns in health terms and the role that food/nutrients played in the development of disease.

Subsequently the findings were quantified by means of a nationally representative quota sample of 505 adults over the age of 16 years.

\section{Research Study}

The analysis of the qualitative research exercise identified that consumers are primarily concerned with four issues as far as food and health are concerned.

Firstly, there is a strong concern with the whole issue of naturalness in food. 'Natural food' or 'the natural diet' is definitely regarded as the best! It is, if you like, as defined by the British Nutrition Foundation survey of 1973 the "back to nature feeling'. It involves in attitude terms at least the requirement to go for basic foods; to avoid additives wherever possible; and to attempt to get back to the 'natural order of things'. After all, why should God-ordained foods not result in a satisfactory diet and good health? Thus, natural food is the best prescription for $0029-6651 / 79 / 3^{823-2406 \$ 01.00}$ C 1979 The Nutrition Society 
good health. Equally associated with this is almost an obsession with the purity of food and a suspicion about additives of all sorts.

Secondly, and directly related is the belief that the 'balanced diet' or a 'varied diet' is the best diet to pursue. It is the excesses of too much or too little in total terms or in terms of specific foods which is likely to cause a problem.

Thirdly, it is apparent that there is some association of individual foods with disease or the capacity to resist disease. The prime examples given always relate to dairy foods (or more widely 'fatty foods') and heart disease (sometimes with reference to cholesterol); the carbohydrate/sugar issue and overweight; the fibre story; vitamin C (and hence fruit and vegetables) and resistance to colds. For smallish minorities there is also reference to sugar and diabetes, salt and high blood pressure, diet and arthritis, and so on.

Fourthly, they possess in broad terms a belief in the concept of 'an ideal diet for optimum health'. Consumers seem quite easily to distinguish between an acceptable diet with which you survive (often quite comfortably) and the diet which provides the best protection from and resistance to disease. The diet is seldom viewed in terms of specific nutrients but more in terms of 'proper eating' helps to protect you against a cold, influenza, infections generally, and so on.

In many ways of course these fundamental principles conflict. Dairy products, and especially milk are on the one hand powerful parts of the natural diet, whilst at the same time being associated with specific diseases. Sugar is bad for you but essential for children to obtain 'energy'.

This should not in itself be seen as surprising. In some senses it reflects attitudes built up over many generations and which are not readily rejected at an emotional level, whatever science/education now tells us. Equally, as has been identified for many years, attitudes and behaviour often differ. People can quite happily disclaim on the merits of a natural diet whilst eating a convenience meal, heavily processed and containing many additives. Moreover they may give positive lip-service to one view without seeing either the need to actively pursue it or believing that the alternative is positively harmful.

There is one further reason for consumers taking and accepting these apparently contradictory views. Indeed it is a reason which they readily understand even refer to themselves. Time and time again in the qualitative research exercise it was claimed that the nutritionists 'do not know what they are talking about' because 'they are always changing their minds'. The problem seems to emerge at two levels. On the one hand, particularly in the media, scientific principles (say for a low carbohydrate or a low fat diet) are applied and distorted in such a variety of ways and with such an emphasis on gimmicks as to hide from the consumer the basic underlying principles. On the other hand the fact that nutritionists as a group are unwilling to give pronouncements at the current stage of the debate on many issues means that the consumer is left to his own devices and to be influenced by the prognostications of the outrageous.

When questioned concerning the key diseases which concern the population at the end of the nineteen-seventies, these emerged predictably to be cancer, 'heart 
trouble', arthritis, blood pressure, 'strokes', pneumonia and bronchitis and so on.

As indicated earlier, some relationship has already been identified by the consumer between some of these diseases and diet. But others are seen to have only small or no relationship. More generally a good diet is seen as protective. This may mean that it helps you better to resist 'getting' disease; better to 'throw off an illness once contracted; and better to convalesce.

Thus the qualitative research exercise provided some understanding of the parameters within which the consumer operates. It was then necessary to undertake a quantified study to isolate the relative weight given to some of these matters. This involved a nationally representative quota sample of 505 adults over 16 years of age, with sub-quotas set for male and female, social class and different age groups in line with the IPA regulations.

Firstly respondents were shown a list of ten 'health problems' and asked to indicate which was the most important. The results indicate that nearly half of the sample $(46 \%)$ believe cancer is the most important, followed by 'heart trouble' $(22 \%)$. An indication of the most significant diseases from the consumers' viewpoint can best be achieved by collating the total answers given by each consumer when probed regarding the most important, second most and next important health problem (Table 1 ). These indicate the significance attributed by the consumer to cancer, 'heart trouble', overweight, arthritis and drug addiction. It is evident that there is a good deal of variation between sex, age, social class, and to some extent region. Thus, in the south, heart trouble is seen as much a problem as is cancer, and arthritis is given greater weight in the north.

Subsequently respondents were then asked to identify which of these health problems were to any extent influenced by food consumption (Table 2). Not surprisingly overweight comes top of the list, but there are significant levels indicated for heart trouble (47\%), and high blood pressure (28\%). Diabetes is also seen at a significant level ( $19 \%$ ). The 26-44 year age group shows a particular concern with the issue of 'heart trouble' and younger people generally refer more to

\section{Table I. Assessment of important health problems}

(Expressed as a percentage of the population mentioning each disease)

\begin{tabular}{lcccccccc} 
Disease & \multicolumn{2}{c}{$\overbrace{\text { Men }}$} & Total & Women & $\overbrace{\mathrm{ABC}}$ & $\mathrm{C}_{2} \mathrm{DE}$ & $\overbrace{\text { North }}^{\text {Social }}$ & South \\
Cancer & 78 & 82 & 77 & 77 & 91 & 80 & 76 \\
Heart trouble & 71 & 82 & 67 & 79 & 66 & 66 & 76 \\
Overweight & 33 & 38 & 31 & 38 & 27 & 32 & 34 \\
Arthritis & 33 & 29 & 35 & 35 & 27 & 29 & 26 \\
Drug addiction & 24 & 15 & 31 & 20 & 26 & 22 & 25 \\
High blood pressure & 24 & 27 & 23 & 24 & 25 & 24 & 25 \\
Alcoholism & 19 & 24 & 15 & 19 & 19 & 20 & 15 \\
Tuberculosis & 3 & 2 & 3 & 2 & 4 & 2 & 4 \\
Diabetes & 10 & 1 & 7 & 7 & 10 & 10 & 9 \\
Asthma & 7 & 5 & 9 & 4 & 7 & 7 & 8 \\
Base & 505 & 244 & 251 & 202 & 303 & 250 & 255
\end{tabular}


Table 2. Health problems to which foods contribute

(Expressed as a percentage of the population mentioning each disease)

\begin{tabular}{|c|c|c|c|c|c|c|c|c|}
\hline \multirow[b]{2}{*}{ Disease } & \multirow[b]{2}{*}{ Total } & \multicolumn{2}{|c|}{ Sex } & \multicolumn{2}{|c|}{ Social Class } & \multicolumn{3}{|c|}{ Age } \\
\hline & & Men & Women & $\mathrm{ABC}_{1}$ & $\mathrm{C}_{2} \mathrm{DE}$ & $16-25$ & $26-44$ & $45+$ \\
\hline $\begin{array}{l}\text { Overweight } \\
\text { Heart trouble } \\
\text { High blood pressure }\end{array}$ & $\begin{array}{l}54 \\
47 \\
28\end{array}$ & $\begin{array}{l}32 \\
56 \\
21\end{array}$ & $\begin{array}{l}64 \\
43 \\
30\end{array}$ & $\begin{array}{l}59 \\
55 \\
31\end{array}$ & $\begin{array}{l}51 \\
42 \\
26\end{array}$ & $\begin{array}{l}59 \\
43 \\
33\end{array}$ & $\begin{array}{l}67 \\
59 \\
34\end{array}$ & $\begin{array}{l}44 \\
40 \\
21\end{array}$ \\
\hline Diabetes & 19 & 15 & 21 & 22 & 20 & 22 & 25 & 13 \\
\hline Cancer & 12 & 15 & II & 12 & 12 & 10 & 16 & 10 \\
\hline Arthritis & 5 & 3 & 8 & 5 & 8 & 2 & 8 & 7 \\
\hline Alcoholism & 5 & 3 & 5 & 6 & 4 & 7 & 7 & 3 \\
\hline Asthma & 3 & 3 & 2 & 4 & 3 & I & 6 & 2 \\
\hline Tuberculosis & 2 & 3 & 2 & 2 & 2 & 2 & 2 & 2 \\
\hline Drug addiction & 2 & 3 & I & 2 & $\mathbf{I}$ & $\mathbf{I}$ & 2 & 2 \\
\hline Base & 505 & 244 & $25 I$ & 202 & 303 & 86 & 177 & 242 \\
\hline
\end{tabular}

overweight, 'heart trouble' and high blood pressure. These issues are also stressed more by high social classes than others.

\section{Conclusions}

It emerges that consumers do have a view both as to the key health problems that exist within the UK and the contributory role, if any, which diet makes. Indeed, in terms of Miller's paper earlier today, it can be argued their views are reasonably accurate, especially if the question of dental caries is excluded as not being a 'killer'.

However, it was very evident from the qualitative research that this does not mean that consumers are able or willing to identify priorities for research. Their views are not only coloured too much by their personal experiences at a given moment in time, but also, and perhaps more importantly, they find it difficult to understand that there is a limited national budget that makes it inevitable that one activity can only be pursued at the expense of another. However, in spite of this there is of course implicit strong support for any political decision to redirect funds towards the health area and to the role which nutrition is seen to play within it.

I believe the study also identifies an additional research priority for us. Such knowledge as the consumer does possess in the nutrition field might be argued to be almost without regard to the expert, whom I have pointed out rarely wishes to pronounce in this area. But the consumer requires reassurance that the views they hold are correct. They also wish to feel that any proposed modification of behaviour as a result of their increased knowledge will not damage their life style. Increasingly they also recognize the problems of achieving a desired change within the family. In this sense they need 'help to help themselves' to follow a diet which will be in the best interests of nutrition and health and to make it as palatable as possible. This enters an area of activity which at present we are ill equipped to handle. 
Vol. $3^{8}$

\section{REFERENCES}

Brown, A., McKenzie, J. \& Yudkin, J. (1963). Nutrition 17, 16.

McKenzie, J. (1965). Market Research Soc. 7.

UK Margarine and Shortening Manufacturers Association (1969). Food Facts and Fallacies.

British Nutrition Foundation (1973). Food and Nutrition, Report on a survey of Housewives' Knowledge and Attitudes. London: British Nutrition Foundation. 